Review

\title{
Current ECG Aspects of Interatrial Block
}

\author{
Antoni Bayés-de-Luna ${ }^{1, * \mathbb{D}}$, Miquel Fiol-Sala ${ }^{2}$, Manuel Martínez-Sellés ${ }^{3,4} \mathbb{D}$ and Adrian Baranchuk 5 \\ 1 Cardiovascular Research Foundation, Cardiovascular ICCC- Program, Research Institute Hospital de la Santa \\ Creu i Sant Pau, IIB-Sant Pau, 08025 Barcelona, Spain \\ 2 Illes Balears Health Research Institut (IdISBa), Hospital Son Espases, 07120 Palma, Spain; \\ miquelfiol@yahoo.es \\ 3 Cardiology Department, Hospital General Universitario Gregorio Marañón, Calle Doctor Esquerdo, 46, \\ 28007 Madrid, Spain; mmselles@secardiologia.es \\ 4 Medical School of the Complutense, University of Madrid, 28040 Madrid, Spain \\ 5 Department of Cardiology, Queen's University, Kingston, ON K7L 3N6, Canada; \\ adrian.Baranchuk@kingstonhsc.ca \\ * Correspondence: abayes@santpau.cat; Tel.: +34-93-556-56-12
}

Citation: Bayés-de-Luna, A.; Fiol-Sala, M.; Martínez-Sellés, M.; Baranchuk, A. Current ECG Aspects of Interatrial Block. Hearts 2021, 2, 419-432. https://doi.org/10.3390/ hearts2030033

Academic Editor: Peter Macfarlane

Received: 19 July 2021

Accepted: 6 September 2021

Published: 8 September 2021

Publisher's Note: MDPI stays neutral with regard to jurisdictional claims in published maps and institutional affiliations.

Copyright: (c) 2021 by the authors. Licensee MDPI, Basel, Switzerland. This article is an open access article distributed under the terms and conditions of the Creative Commons Attribution (CC BY) license (https:// creativecommons.org/licenses/by/ $4.0 /)$.

\begin{abstract}
Interatrial blocks like other types of block may be of first degree or partial second degree, also named transient atrial block or atrial aberrancy, and third degree or advanced. In first degree, partial interatrial block (P-IAB), the electrical impulse is conducted to the left atrium, through the Bachmann's region, but with delay. The ECG shows a P-wave $\geq 120 \mathrm{~ms}$. In third-degree, advanced interatrial block (A-IAB), the electrical impulse is blocked in the upper part of the interatrial septum (Bachmann region); the breakthrough to LA has to be performed retrogradely from the AV junction zone. This explains the $\mathrm{p} \pm$ in leads II, III and aVF. In typical cases of A-IAB, the P-wave morphology is biphasic $( \pm)$ in leads II, III and aVF, because the left atrium is activated retrogradely and, therefore, the last part of the atrial activation falls in the negative hemifield of leads II, III and aVF. Recently, some atypical cases of A-IAB have been described. The presence of A-IAB is a risk factor for atrial fibrillation, stroke, dementia, and premature death.
\end{abstract}

Keywords: interatrial block; partial interatrial block; advanced interatrial block; atypical patterns

\section{Introduction}

The diagnosis of different types of atrioventricular (AV) and ventricular blocks is well known and is explained in most cardiology and clinical electrocardiography books [1-4]. However, the ECG diagnosis of blocks at the atrial level based in changes of morphology and duration of the P-wave, although established many years ago [5], is sometimes even not mentioned in some books of clinical ECG [6]. The P-wave still remains the ECG Cinderella. We will review in this chapter the most important aspects related with blocks at the atrial level.

Usually, atrial blocks are located at the interatrial level and, like other types of blocks, could be classified as first degree or partial (P-IAB), second degree or transient, and third degree or advanced (A-IAB) (Figure 1).

Bachmann [7] published the first ECG of partial-IAB in 1944, and Puech [8] published the first case of advanced-IAB in 1956. In the following three decades, only small series or isolated cases were published [9-12]. Finally, in 1985 [5], our group published the ECG-VCG criteria of A-IAB in a series of 88 cases, and three years later in 1988 [13] we published for the first time that patients with A-IAB, compared with a control group of patients with $\mathrm{P}-\mathrm{IAB}$, were associated with a much higher incidence of atrial fibrillation (AF) during the follow-up.

In the following 15 years not many papers were published. Only our group [14,15] and the groups of Spodick [16], Garcia-Cosio [17] and Platonov [18] published some papers on this topic. 


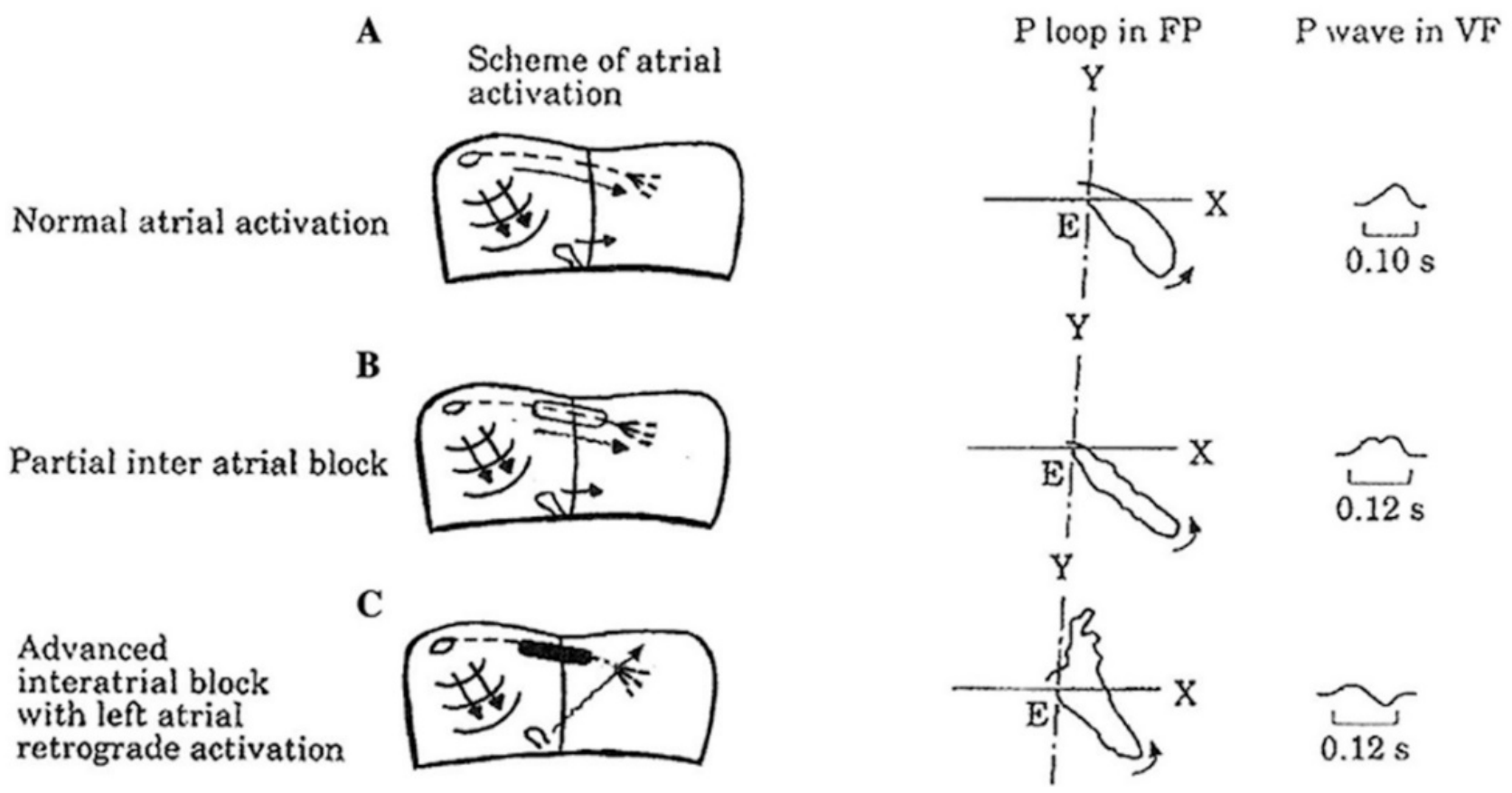

Figure 1. (A) Diagram of atrial conduction under normal circumstances; (B) partial interatrial block, and (C) typical advanced interatrial block with left atrial retrograde activation (IAB with LARA).

The poor knowledge about IAB is probably because it was considered that IAB was equivalent to left atrial enlargement. In 2012 we published a consensus document [19] that stated that $p \geq 120 \mathrm{~ms}$ was explained by a delay of conduction between the right and left atrium, accomplishing the three conduction principles that are required for an ECG pattern to be considered a block: (i) the ECG pattern may be transient [20]; (ii) the ECG pattern may be experimentally reproduced [21,22]; and (iii) the ECG pattern may exist in the absence of cardiac enlargement and ischemic heart disease [5].

Furthermore, in the last few years, we have demonstrated some other important features associated with IAB knowledge: (i) ECG criteria for typical and atypical patterns of IAB [23]; (ii) atrial fibrosis is the most frequent anatomic substrate [24,25]; (iii) clinical associations with not only AF, but also stroke, dementia and mortality [26].

\section{ECG Diagnosis of Interatrial Blocks (IAB)}

\subsection{How to Measure P-Wave Duration?}

The measurement of the P-wave [27] and the diagnosis of IAB may be conducted at a first glance if the ECG recording and the morphology of the P-wave in leads II, III, and aVF are clear and free of artifact or pacing spikes. Sometimes, measurements can be difficult due to low voltages and consistency on the measurements is key. Analyzing digital ECG images using amplification is paramount. The use of ECG recording systems that allow at least three simultaneous channels (six or twelve channels) is ideal.

Particular attention should be given to the six leads of the frontal plane, if possible, at the same time, because this is where we will better identify the changes of the P-wave duration and of morphology produced by IAB (biphasic P-wave).

It is also recommended to measure the $p$ terminal force in V1 (PtfV1) [28] as it is considered an extremely specific criterion for the diagnosis of associated left atrial enlargement (LAE). However, the morphology of PtfV1 presents significant variations depending on the location of the V1 precordial electrode [29]. This may explain, at least in part, the recent negative results obtained using the value of PtfV1 as a risk factor for ischemic stroke [30].

To perform a good P-wave duration measurement, it is important to check and define the interval between the earliest detection of the P-wave (onset) in any lead of the frontal plane, and the latest one (offset). Once these two points are defined with lines, the P- 
wave duration can be measured using calipers or semi-automatic calipers such as the ones provided by Geogebra program, although in clinical practice the duration and morphology of the P-wave may be obtained at first glance.

\subsection{First Degree (Partial) Interatrial Block}

The electrical impulse is conducted normally from the right atrium to the left atrium, through the Bachmann's region, but with delayed conduction. Therefore, the ECG shows a P-wave $\geq 120 \mathrm{~ms}$ (Figure 1) (Table 1).

Table 1. ECG classification of interatrial blocks (IAB).

1. Partial Interatrial Block (First Degree) (P-IAB)

$\mathrm{P}$-wave $\geq 120 \mathrm{~ms}$ without negative terminal component in the inferior leads

2. Advanced interatrial block (third degree) (A-IAB)

Typical pattern

P-wave $\geq 120$ ms with biphasic morphology in leads II, III aVF $( \pm)$

Atypical A-IAB may be atypical by morphology or by duration:

(i): Morphological criteria

Type 1: P-wave $\geq 120 \mathrm{~ms}$ with biphasic morphology in leads III and aVF and the final component of the P-wave in lead II is isodiphasic.

Type 2: P-wave $\geq 120 \mathrm{~ms}$. The second part of The P-wave is biphasic $(\mp)$. This means that the global P-wave is triphasic $(+-+)$.

Type 3: P-wave $\geq 120 \mathrm{~ms}$. The first part of P-wave in leads III and aVF is isoelectric, but the last part is negative. Therefore, it is necessary to perform differential diagnoses with junctional rhythm.

(ii) Duration criteria

P-wave $<120$ ms with typical morphology (Biphasic ( \pm ) P-wave in leads II, III, and aVF)

\section{Second degree: The presence of ECG pattern of IAB is intermittent}

\subsection{Third-Degree (Advanced) Interatrial Block}

The electrical impulse is blocked in the upper part of the interatrial septum (Bachmann's region), and as the rest of the septum is predominantly connective tissue, the breakthrough to LA is achieved retrogradely from the AV junction zone or other near zones [5,18]. This explains the $p \pm$ in leads II, III and aVF (Figure 1C) (Table 1).

There is an experimental validation of this phenomenon. As we have already commented, Waldo et al. [21], first in 1971, demonstrated that by cutting the Bachmann's region at both sides of the septum in dogs the biphasic pattern can be reproduced. More recently, Guerra et al. [22] provoked transient A-IAB by applying ice in an open chest (pig model), reproducing transient morphology from normal $\mathrm{P}$-wave to $\mathrm{P}-\mathrm{IAB}$ and $\mathrm{A}-\mathrm{IAB}$ and resolution after normalization of temperature (Figure 2).

\subsubsection{Typical ECG Pattern}

The ECG of typical IAB shows (Figures 3C and 4) a P-wave $\geq 120 \mathrm{~ms}$ with biphasic $( \pm)$ morphology in leads II, III, and aVF, due to caudocranial activation of the left atrium. Our group defined the ECG-VCG criteria in a large series of patients and demonstrated that this type of pattern is associated with LAE in $90 \%$ of the cases [5]. 


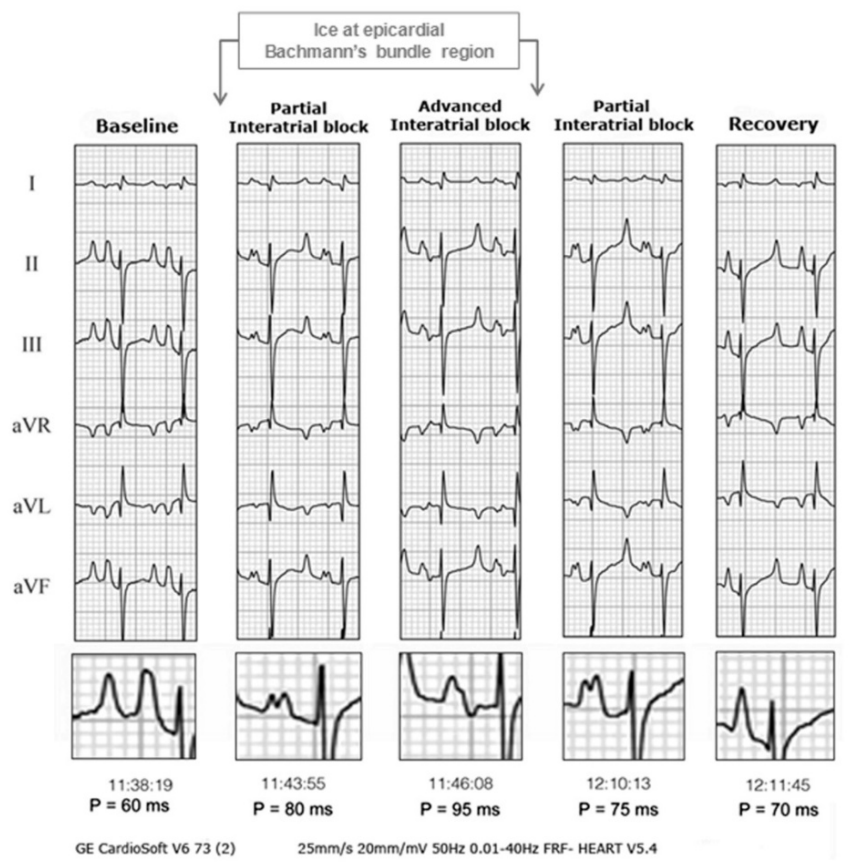

Figure 2. Transient changes of P-wave recorded in lead II after applying ice to the Bachmann's region. Surface electrocardiogram (ECG) of an open-chest anesthetized healthy adult swine, before, during, and after direct application of ice at the transversus sinus of the pericardium (Bachmann's region). A change in P-wave duration and morphology, constituting a transient interatrial block (IAB), is observed as rapidly evolving from partial to advanced IAB (A-IAB). Subsequently, as the ice melts, the ECG pattern normalizes. Please note that P-wave duration in pigs is different (shorter) than in humans. (Taken from reference 22).

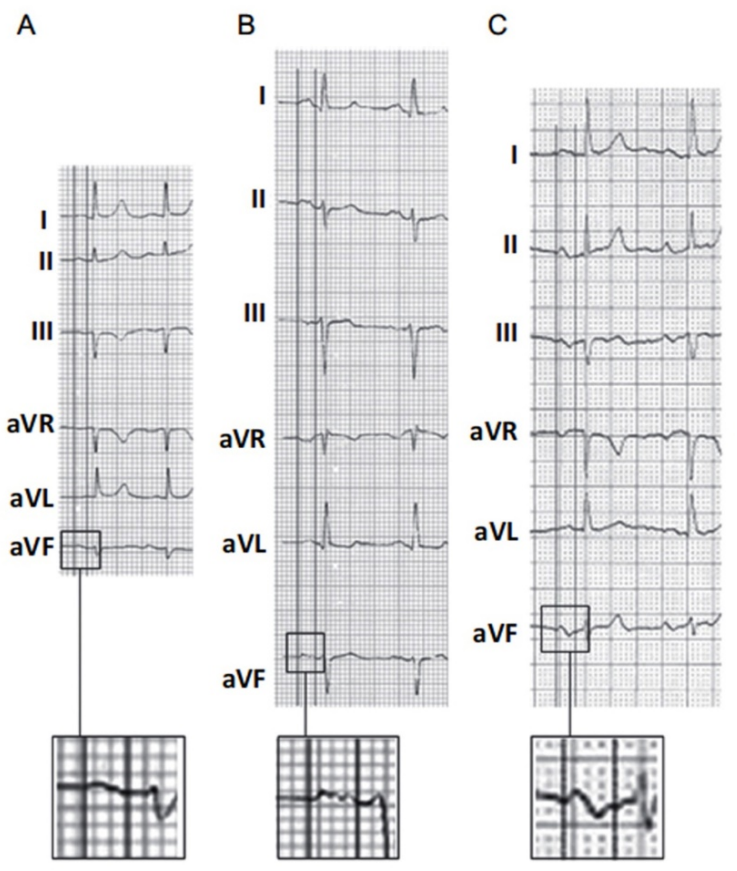

Figure 3. Examples of the 3 types of atrial activity: (A) normal P-wave (P-wave duration $<120 \mathrm{~ms}$ ), (B) partial interatrial block (P-wave duration $\geq 120 \mathrm{~ms}$ ), (C) advanced interatrial block (P-wave duration $\geq 120 \mathrm{~ms}$ with biphasic morphology (+/ - in leads II, III, and aVF). 


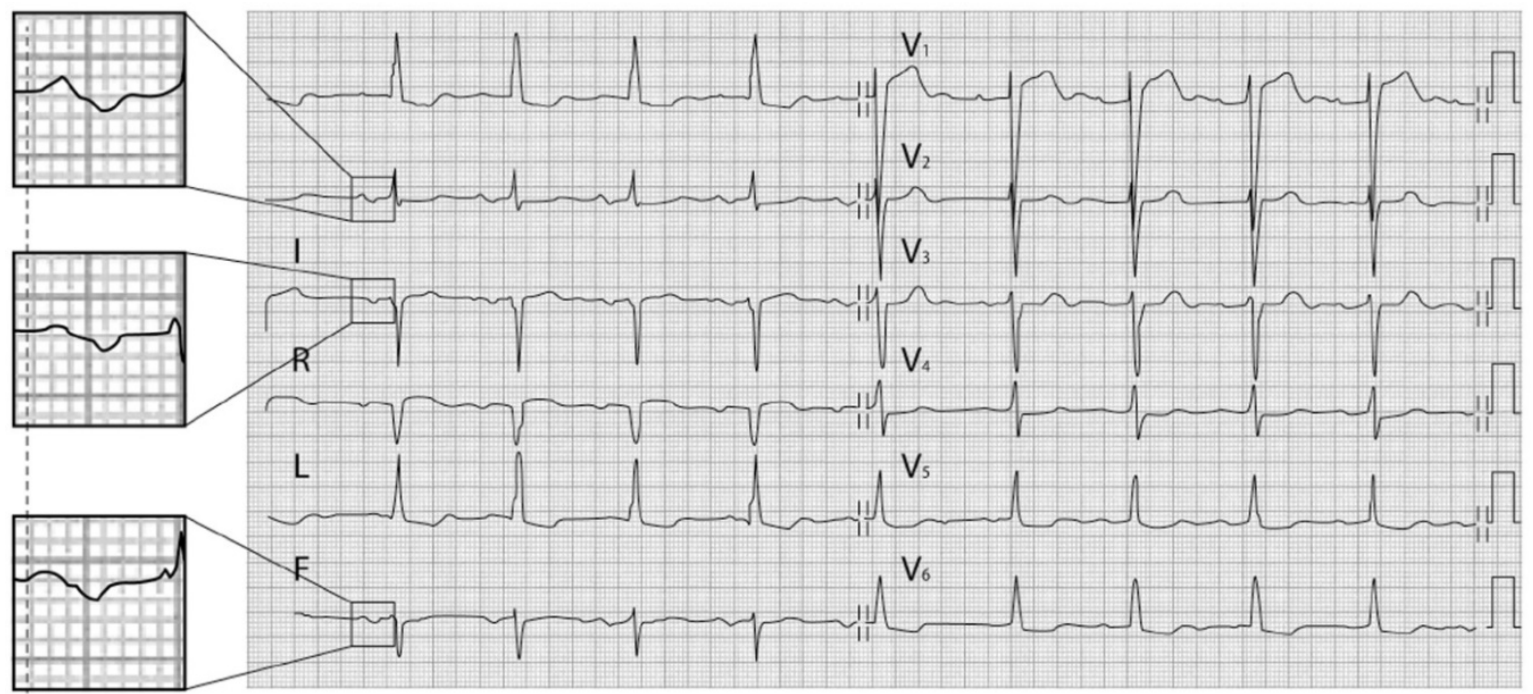

Figure 4. Typical ECG of advanced interatrial block (P-wave \pm in leads II, III, and aVF and duration $\geq 120 \mathrm{~ms}$ ) in a patient with ischemic heart disease. When amplified (left) we can see the beginning and the end of the P-wave in the three leads.

Figure 5 shows $(\mathrm{A}, \mathrm{B})$ the typical ECG and VCG pattern, with \pm P-wave morphology in leads II and III, and an open VCG loops in frontal plane (FP) and right sagittal plane (RSP) with the final part of the loops upwards. (B). This figure also shows (C) that the atrial stimulus moves first downwards (HRA-LRA) and after upwards (LRA-high esophageal).

A

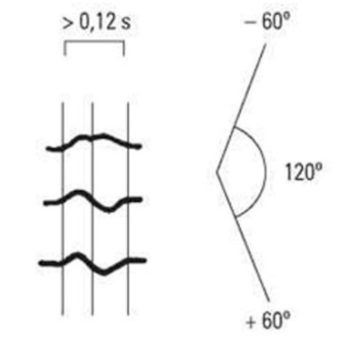

B

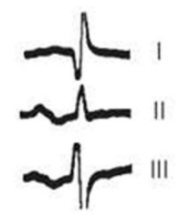

$20^{\circ}$

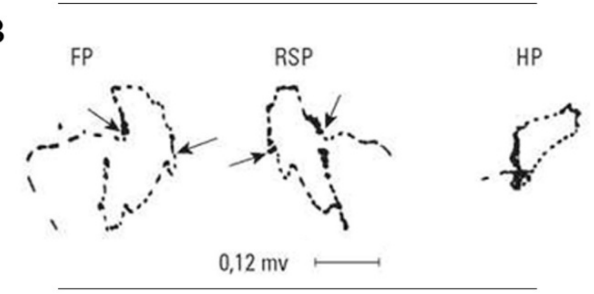

$\mathrm{C}$

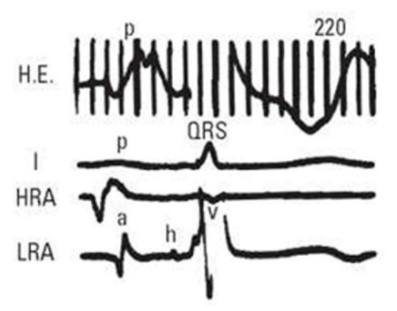

Figure 5. (A). P-wave \pm morphology in leads II and III typical of advanced IAB with retrograde conduction to the left atrium. Note how the ÂP and the angle between the direction of the activation in the first and second parts of the P-wave are measured. (B). Note also the open $P$ loops with the last part upwards (FP and RSP). (C). Intra-esophageal ECG (HE) and endocavitary registrations (HRA: high right atrium; LRA: low right atrium) demonstrate that the electrical stimulus moves first downwards (HRA-LRA) and then upwards (LRA-HE). (Taken from reference 5). 
Figure 6 shows the endocardial mapping in a case of A-IAB, with the caudocranial activation of the LA.

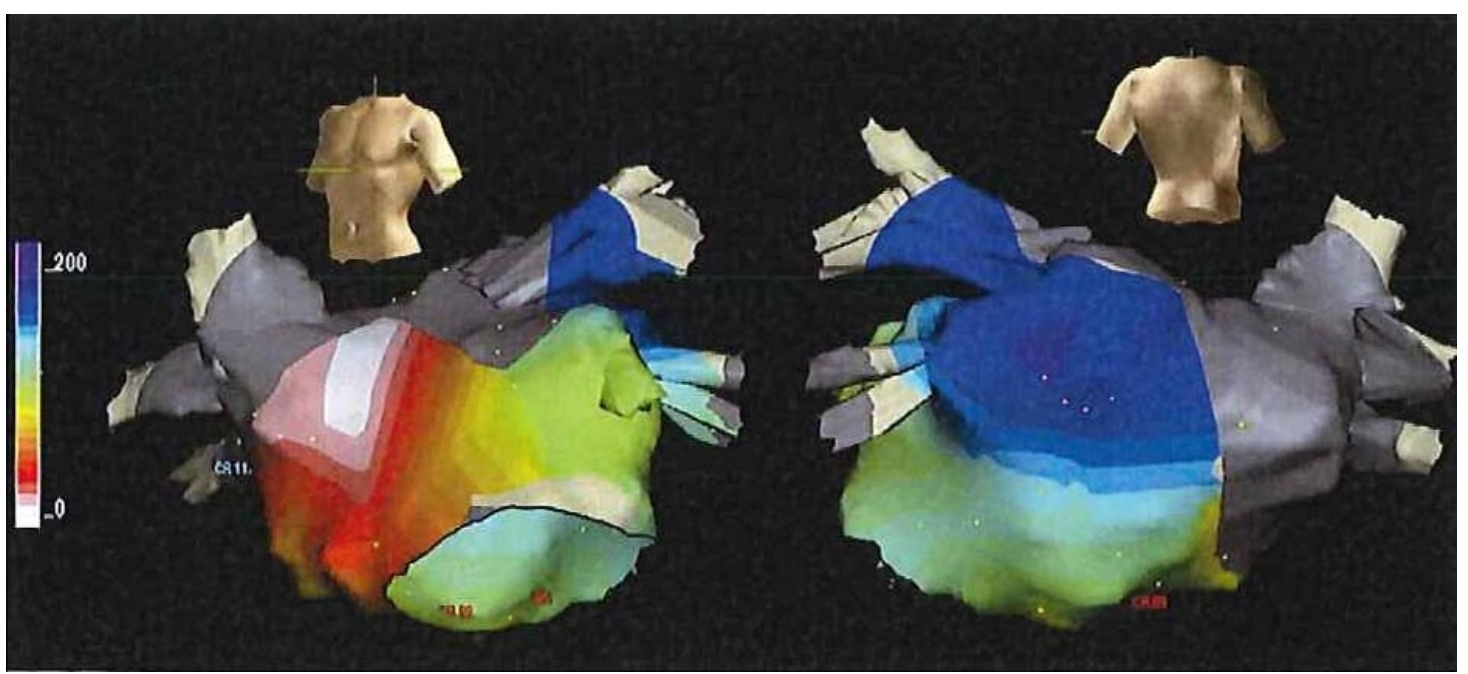

Figure 6. Virtual anatomic rendering of the LA in a patient with typical biphasic ( \pm ) P-wave in leads II, III, and aVF suggestive of A-IAB (Bachmann's region block). Note that early left atrial activation (white) occurs at the high septal wall, as expected for Bachmann region conduction. Activation does not progress through the left atrial roof because of the presence of a large zone of low voltage (gray) that diverts activation toward the low septal (orange-yellow) then the low posterior (green) and finally the high posterior (violet) left atrial wall. (Taken from reference 19).

We demonstrated in 1988 (Figure 7) [13] that this type of A-IAB is frequently associated with atrial fibrillation and/or atrial flutter during follow-up, especially in patients with prior heart disease. This association has been named Bayes' syndrome [27,31].

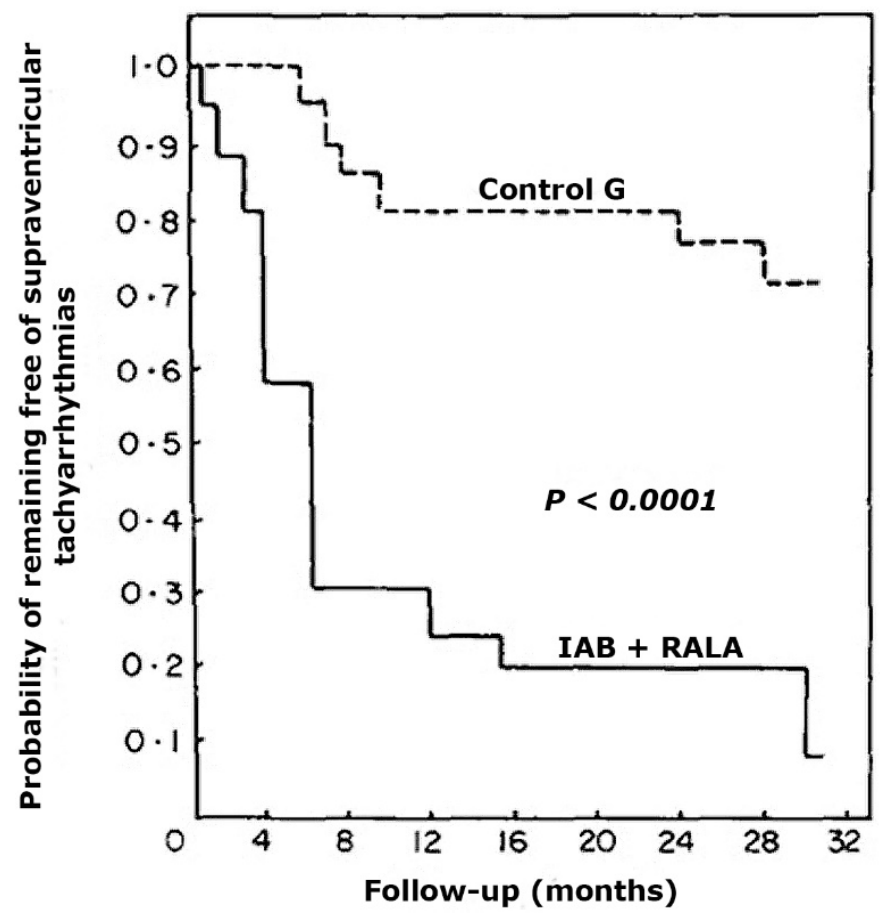

Figure 7. Probability of remaining free of supraventricular tachyarrhythmias (atrial flutter and atrial fibrillation) in patients with advanced interatrial block (IAB) and controls (partial IAB). (Take from reference 13 ). 


\subsubsection{Atypical Patterns}

During the review of ECGs belonging to different cohorts (Heart Failure [32], BAYES Registry [33,34], REGICOR [35], Centenarians [36]), we realize that some P-wave ECG patterns are very similar to typical A-IAB patterns, but present some minor differences of morphology and duration of P-wave. We consider that these are of atypical patterns of A-IAB (Figures 8-11) (Table 1).

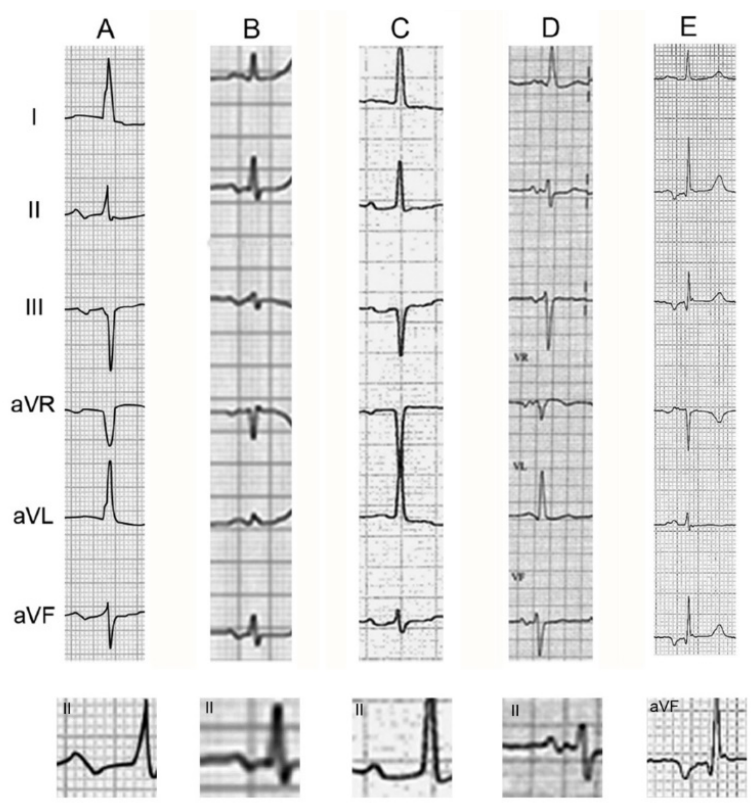

Figure 8. (A). Typical A-IAB. (B). Atypical A-IAB by duration. (C). Type 1 atypical A-IAB due to morphology. The P-wave is biphasic in leads III, and aVF, but the terminal component of the $\mathrm{P}$ wave in lead II is isodiphasic. (D). Type II atypical A-IAB. The P-wave is biphasic in leads III and aVF, but triphasic in lead II $(+-+)$. (E). Type III atypical A-IAB. The P-wave morphology is negative in leads III and aVF, and biphasic in lead II with the initial component of the P-wave in leads III and aVF isodiphasic. (Taken from reference 23).

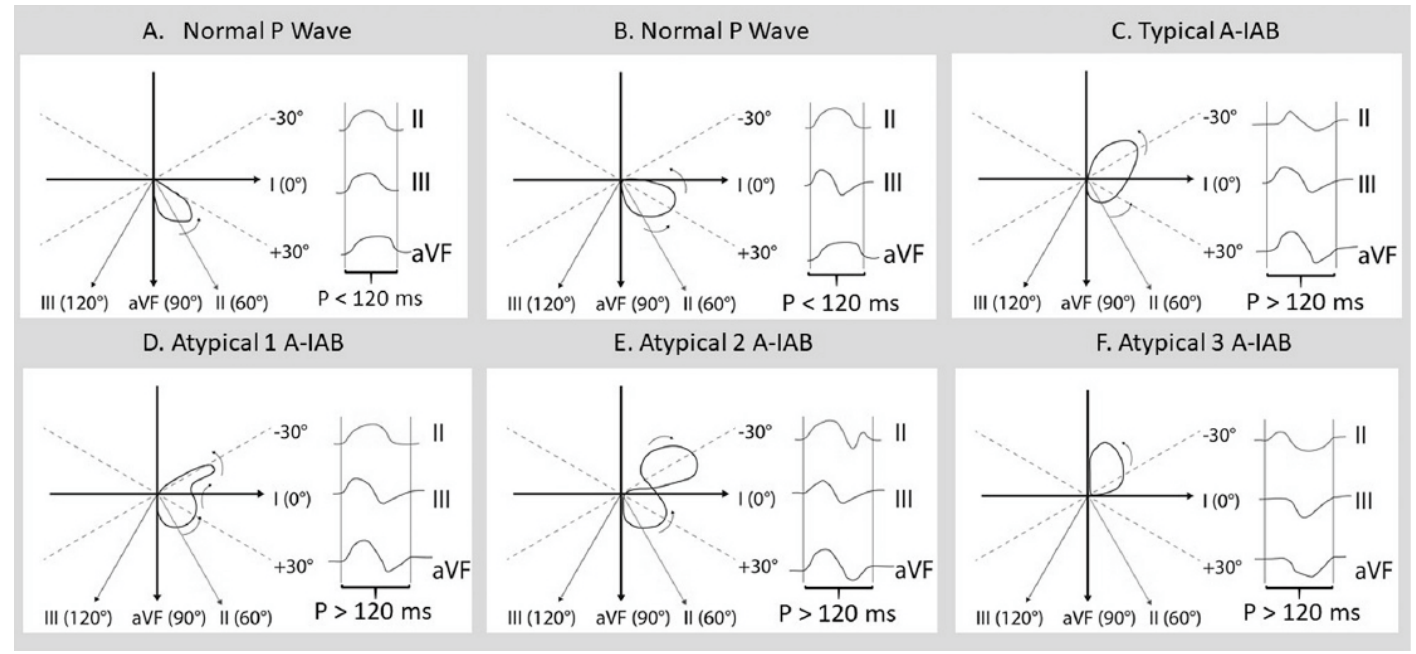

Figure 9. (A,B): Normal P-waves. In panel B, there is a biphasic $( \pm)$ pattern in lead III. This is considered normal because the last part of the P loop falls in the negative hemifield of lead III, that start at $+30^{\circ}$ but it is positive in leads II and aVF, because the P loop falls in positive hemifield of these leads that starts $-30^{\circ}$ and $0^{\circ}(\mathrm{C})$ typical A-IAB. The second part of the P loop falls in the negative hemifield of leads II, III and aVF. (D-F): the 3 atypical A-IAB patterns by morphology. (Taken from reference 23). 

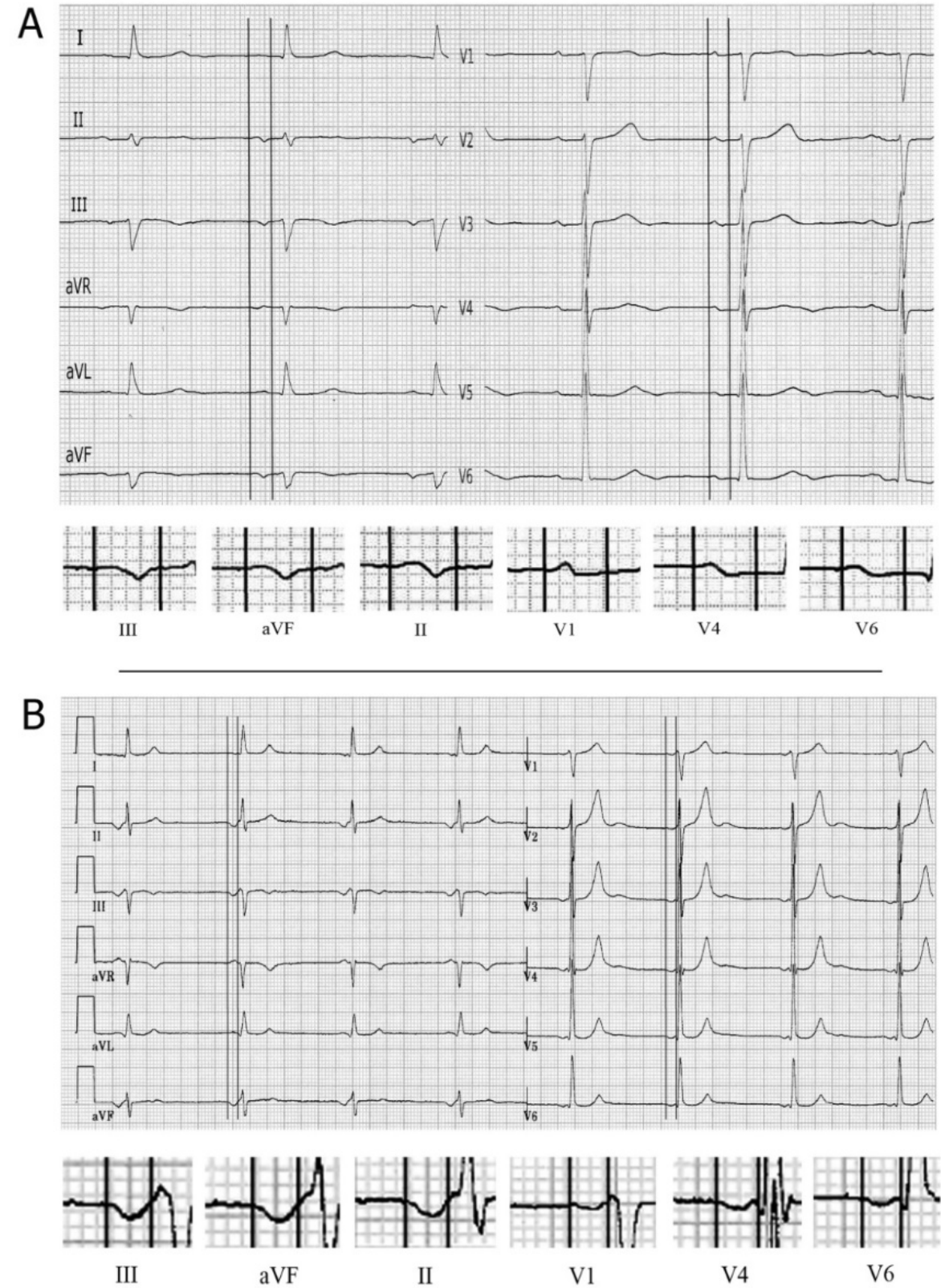

Figure 10. (A) P-wave in a case of A-IAB atypical type 3 by morphology. Note that the P-wave is negative in III and aVF, but with a first part isodiphasic as may be seen with vertical lines. It may be confused with junctional rhythm, but in this case (see B) all the P-wave is negative and, furthermore, the P-wave is also negative in V4-V6. (Taken from reference 37).

A-IAB exists when there is evidence that at least part of the left atrium is activated retrogradely. This may be ensured if the last part of aVF is negative because this represents that the last part of the loop fall in the negative hemifield of aVF (beyond $0^{\circ}$ ) (Figure 9C-F). This is the key point to assure that there is retrograde activation of the LA.

In typical cases of A-IAB, the P-wave morphology is \pm in leads II, III and aVF because the last part of the atrial activation falls in the negative hemifield of leads II, III and aVF, and the duration of the P-wave is $\geq 120 \mathrm{~ms}$.

However, there are atypical patterns of A-IAB with some morphological changes in leads II, III and aVF, but always with final negative component in aVF and $p$ duration $\geq 120 \mathrm{~ms}$, or a P-wave pattern \pm in leads II, III and aVF but with duration of P-wave less than $120 \mathrm{~ms}$. 

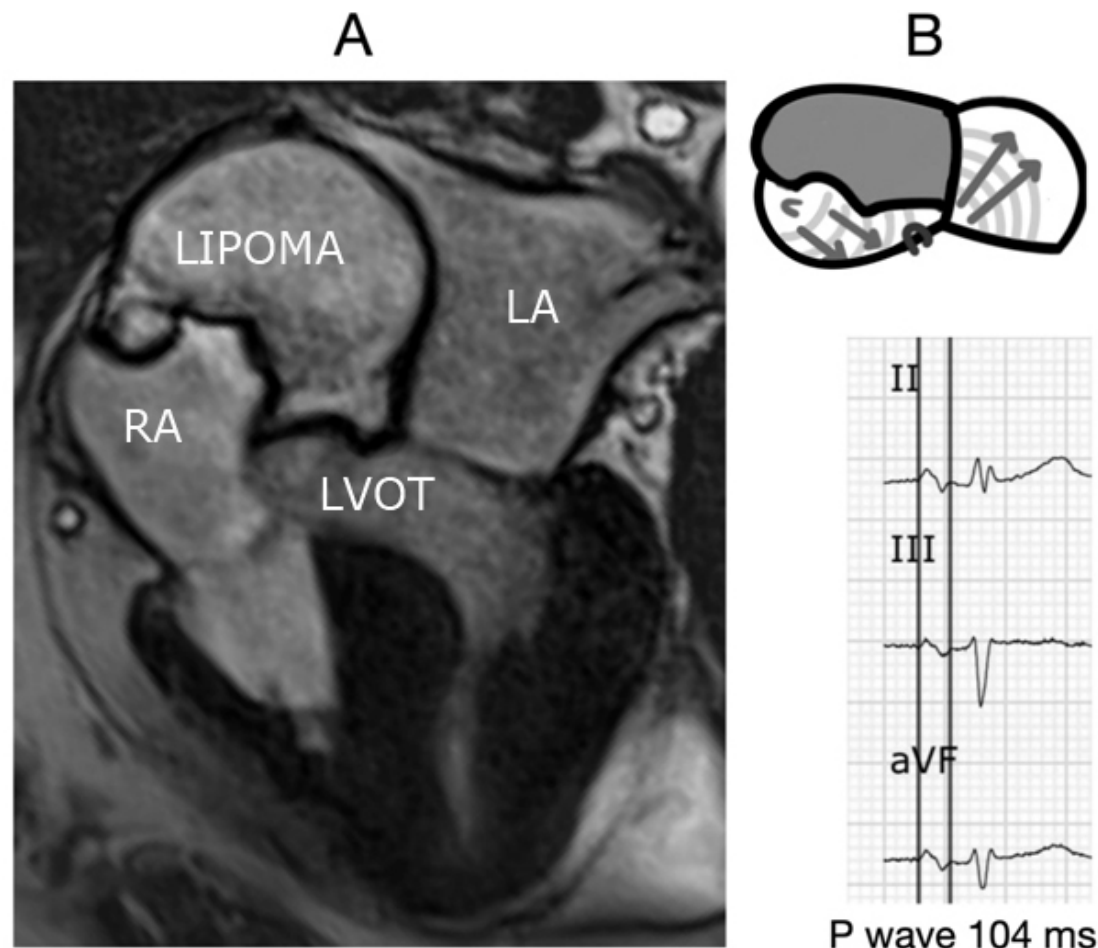

Figure 11. (A,B) A case of a 73-year old man found to have a large lipoma $(4 \times 5 \mathrm{~cm})$ located on the interatrial septum. Cardiac magnetic resonance imaging allowed for complete characterization. As the atrial fibrosis is not extended in all atria, the duration of the P-wave in spite of A-IAB is $<120 \mathrm{~ms}$. (Taken from reference 38).

\subsubsection{Atypical A-IAB Due to Changes in P-Wave Morphology}

(i) Type I: The P-wave in leads III and aVF remain biphasic $(+/-$. However, the terminal component of the P-wave in lead II is isoelectric (Figures 8C and 9D). Therefore, P-wave in lead II presents positive pattern.

(ii) Type II: The second part of the P-wave in lead II is biphasic ( $\mp)$, therefore, the P-wave is triphasic $(+-+)$ (Figures $8 \mathrm{D}$ and $9 \mathrm{E})$.

(iii) Type III (Figures 8E and 9F) The P-wave morphology in leads III and aVF is completely negative, but started being isodiphasic, and the P-wave in lead II is biphasic $( \pm)$. This pattern requires a differential diagnosis with junctional rhythm (Figure 10) [37]. If the polarity of the P-waves in leads V5-V6 is positive, then atypical A-IAB is diagnosed, while if it is negative, then junctional rhythm is the final diagnosis.

\subsubsection{Atypical A-IAB Due to Changes in P-Wave Duration}

In some A-IAB the sinus impulse has to follow a longer path to reach the LA in the absence of fibrosis, as happens in the rare circumstances of an atrial tumor; this blocks the Bachmann bundle. In these cases, the morphology \pm of A-IAB may be explained by the presence of an interatrial block in the Bachmann region due to tumor, but the duration of the P-wave may still last less than $120 \mathrm{~ms}$, because there is not fibrosis in the rest of the atria, including the supplementary routers $[18,38]$ (Table 1) (Figure 11).

\subsection{Second-Degree Atrial Block}

Second-degree interatrial block appears transiently and is usually advanced and, more rarely, partial. It is also known as atrial aberrancy $[39,40]$ when it manifests as P-waves that vary in shape from one beat to another (Figure 12). 


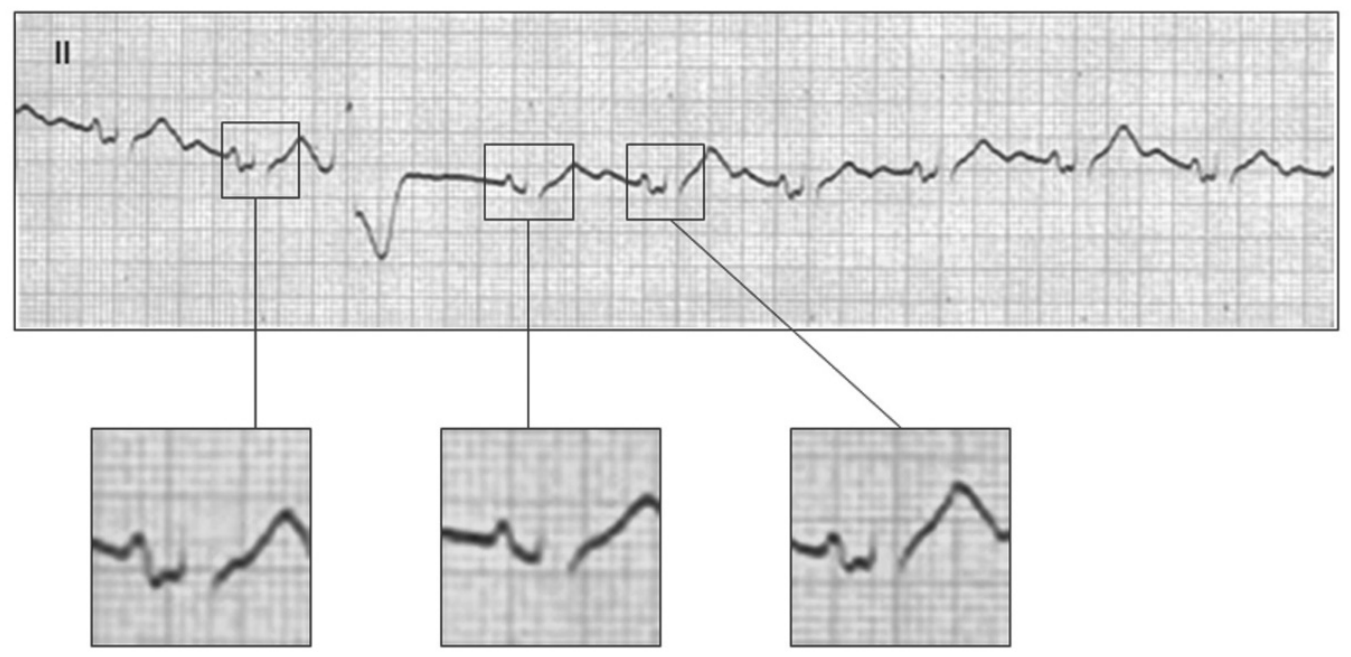

Figure 12. Lead II ECG strip from an 82-year-old man with frequent PVCs. The first two beats show typical advanced IAB (P-wave in lead II is biphasic, with P-wave duration $>120 \mathrm{~ms}$ ). After the premature ventricular contraction (PVC), there is a pause followed by a $\mathrm{P}$-wave of normal duration and morphology. The next $\mathrm{P}$ wave again depicts advanced IAB. This case serves as an example of second degree IAB induced by a pause after a PVC.

This type of interatrial block is more frequently seen in the following circumstances: (a) induced by atrial or ventricular premature complexes (Figure 12); (b) may transiently appear and disappear if frequent ECGs are registered [27,28] (Figure 13).
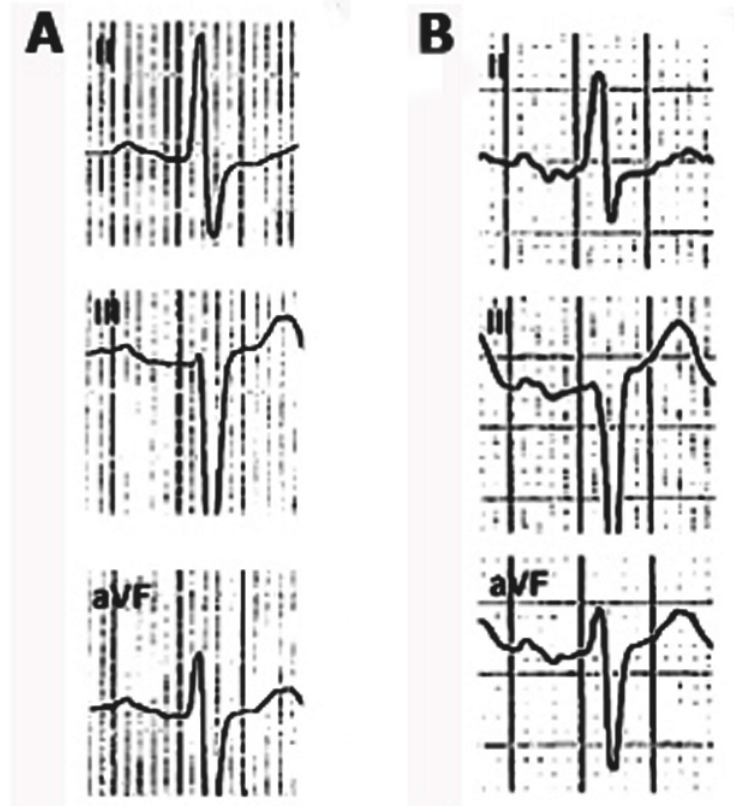

Figure 13. (A) Leads II, III and aVF of a 77-year-old man with hypertrophic cardiomyopathy. Heart rate $70 \mathrm{bpm}$ : P-wave $160 \mathrm{~ms}$ (partial IAB). (B) Same patient was hospitalized due to a febrile episode $\left(39^{\circ}\right)$. The heart rate increased to $100 \mathrm{bpm}$, and the P-wave depicts a typical pattern of advanced IAB (biphasic morphology in leads II, III, and aVF) and duration of $175 \mathrm{~ms}$. The advanced IAB pattern is associated with a tachycardia-dependent (Phase 3) block. This ECG pattern normalized after fever was controlled and heart rate decreased.

Sometimes the interatrial block is progressive (Figure 14). The P-wave changes from normal to $\mathrm{P}-\mathrm{IAB}$ and finally $\mathrm{A}-\mathrm{IAB}$ over time, indicating a progressive fibrosis of the atrium [41]. 

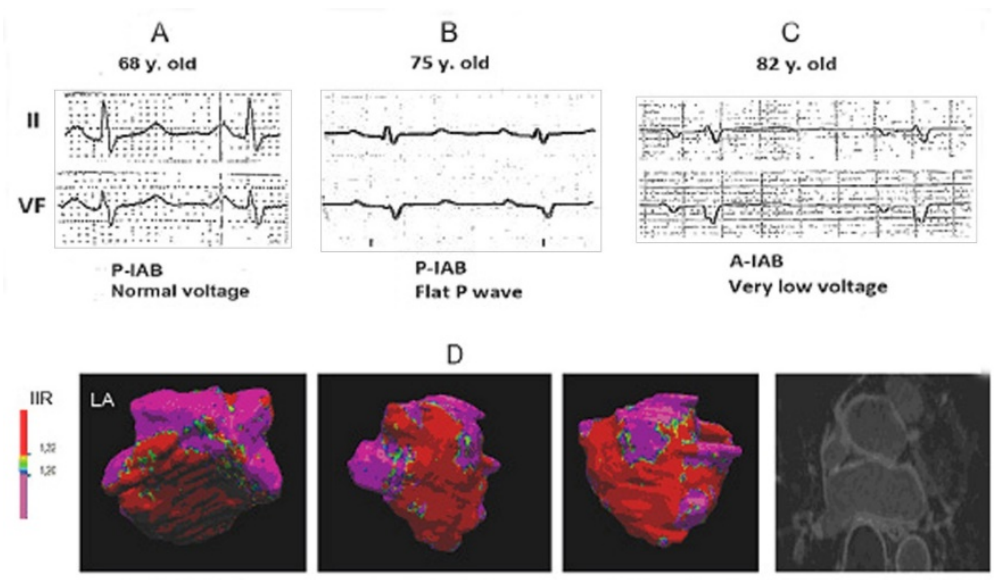

POSTERIOR VIEW

SEPTAL VIEW

ANTERIOR VIEW
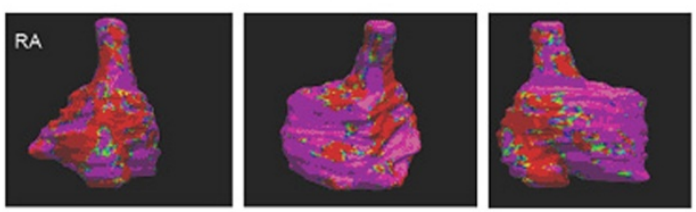

LGE.CMR SEQUENCE

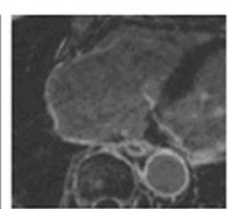

Figure 14. A case that describes the temporal evolution (A-C) of IAB. (A) P-wave of partial IAB to a definitive A-IAB pattern (C) with extremely low voltages. See in the lower part (D), magnetic resonance image with advanced fibrosis.

\section{Clinical Implications}

The first demonstration that A-IAB was a risk factor for supraventricular arrhythmias was the publication by Bayés de Luna et al. [5] who demonstrated that patients with A-IAB presented in a short-term follow-up, a high incidence of atrial fibrillation/flutter compared to the control group who presented with P-IAB. In the following 15 years, it some groups published articles that confirmed these results [42,43].

Baranchuk et al. coined the term Bayes' Syndrome [27] to describe the association of A-IAB and atrial fibrillation/flutter; and many groups [44-50] became also interested in this relationship. In recent years, has been demonstrated that A-IAB (and AF) are risk factors for atrial tachyarrhythmias [13], ischemic stroke [33,37,51], cognitive impairment and dementia $[43,52,53]$ and mortality $[35,54]$.

P-IAB may also be a risk factor for complications, especially if the duration of the P-wave $\geq 150 \mathrm{~ms}$ conveys a three-fold all-cause mortality risk [52].

From a hemodynamic point of view, the IAB produces only small consequences, especially if $\mathrm{P}$-wave duration is not very much altered. On the contrary, A-IAB produces clear changes of activation of the atria which result in hemodynamic consequences.

The challenge is to decide if anticoagulation may be useful to decrease all these complications. A randomized trial is mandatory (oral anticoagulants vs. placebo or aspirin) to determine if this treatment alternative may be beneficial.

Author Contributions: Writing—original draft preparation, A.B.-d.-L., M.F.-S., M.M.-S. and A.B.; writing-review and editing, A.B.-d.-L., M.F.-S., M.M.-S. and A.B.; visualization, A.B.-d.-L., M.F.-S., M.M.-S. and A.B.; supervision, A.B.-d.-L., M.F.-S., M.M.-S. and A.B. All authors have read and agreed to the published version of the manuscript.

Funding: Not applicable.

Institutional Review Board Statement: Not applicable.

Informed Consent Statement: Not applicable.

Data Availability Statement: Not applicable.

Conflicts of Interest: The authors declare no conflict of interest. 


\section{References}

1. Eugene, B. Foreword. In Clinical Electrocardiography. A Textbook, 2nd ed.; Futura Publishing Company, Inc.: Armonk, NY, USA, 1998

2. Fuster, V.; Narula, J.; Harrington, R.A.; Eapen, Z.J. (Eds.) Hurst's The Heart, 14th ed.; McGraw-Hill Education: New York, NY, USA, 2017.

3. Camm, J.; Lüscher, T.F.; Maurer, G.; Serruys, P.W. (Eds.) The ESC Textbook of Cardiovascular Medicine, 3rd ed.; Oxford University Press: Oxford, UK, 2019.

4. Bayés de Luna, A. Clinical Electrocardiography; Wiley-Blackwell: Hoboken, NJ, USA, 2012.

5. Bayés de Luna, A.; de Ribot, R.F.; Trilla, E.; Julia, J.; Garcia, J.; Sadurni, J.; Riba, J.; Sagues, F. Electrocardiographic and vectorcardiographic study of interatrial conduction disturbances with left atrial retrograde activation. J. Electrocardiol. 1985, 18, 1-13. [CrossRef]

6. Strauss, D.G.; Schocken, D.D. Marriott's Practical Electrocardiography, 13th ed.; Wolters Kluwer: Philadelphia, PA, USA, 2021.

7. Bachmann, G. The significance of splitting of the P-wave in the ECG. Ann. Intern. Med. 1941, 14, 1702-1709. [CrossRef]

8. Puech, P. L'activité Électrique Auriculaire. Normale et Pathologique; Masson \& Editeurs: Paris, France, 1956.

9. Castillo Fenoy, A.; Vernant, P. Les troubles de la conduction interauriculaire pour bloc du faisceau du Bachmann. Arch. Mal. Coeur. Vaiss. 1971, 64, 1490-1503.

10. Di Biase, M.; Rizzon, P. Blocco interatriale con attivazione caudocraneale dell'atrio sinistro. G. Ital. Cardiol. 1975, 5, 323.

11. García Civera, R.; Llácer Escorihuela, A.; Benages Martínez, A.; López Merino, V. Estudio de la activación auricular y de la conducción AV en el bloqueo del haz de Bachmann en el corazón humano. [Study of auricular activation and A-V conduction in Bachmann bundle block in the human heart]. Rev. Esp. Cardiol. 1972, 25, 341. [PubMed]

12. Bayés de Luna, A.; Bonnin, O.; Ferriz, J.; Fort De Ribot, R.; Julia, J.; Oter, R.; Trilla, E.; Roman, M.; Vernis, J.; Vilaplana, J.; et al. Trastorno de conducción intraauricular con conducción retrógrada auricular izquierda. Estudio electrocardiológico y clínico a propósito de 24 casos. Rev. Esp. Cardiol. 1978, 31, 173-178. [PubMed]

13. Bayés de Luna, A.; Cladellas, M.; Oter, R.; Torner, P.; Guindo, J.; Martí, V.; Rivera, I.; Iturralde, P. Interatrial conduction block and retrograde activation of the left atrium and paroxysmal supraventricular tachycarrhythmias. Eur. Heart J. 1988, 9, 1112. [CrossRef]

14. Bayés de Luna, A.; Oter, M.C.; Guindo, J. Interatrial conduction block with retrograde activation of the left atrium and paroxysmal supraventricular tachyarrhythmic treatment. Int. J. Cardiol. 1989, 22, 147-150. [CrossRef]

15. Bayés de Luna, A.; Guindo, J.; Viñolas, X.; Martinez-Rubio, A.; Oter, R.; Bayés-Genís, A. Third-degree interatrial block and supraventricular tachyarrhythmias. EP Eur. 1999, 1, 43-46. [CrossRef]

16. Ariyarajah, V.; Puri, P.; Apiyasawat, S.; Spodick, D.H. Interatrial block: A novel risk factor for embolic stroke? Ann. Noninvasive Electrocardiol. 2007, 12, 15-20. [CrossRef]

17. Garcia Cosio, F.; Martín-Peñato, A.; Pastor, A.; Núñez, A.; Montero, M.A.; Cantale, C.P.; Schames, S. Atrial activation mapping in sinus rhythm in the clinical electrophysiology laboratory. Observations in Bachmann's bundle block. J. Cardiovasc. Electrophysiol. 2004, 15, 524-531. [CrossRef]

18. Platonov, P.G.; Mitrofanova, L.B.; Chirreikin, L.V.; Olsson, S.B. Morphology of inter-atrial conduction routes in patients with atrial fibrillation. Europace 2002, 4, 183-192. [CrossRef]

19. Bayés de Luna, A.; Platonov, P.; Cosio, F.G.; Cygankiewicz, I.; Pastore, C.; Baranowski, R.; Bayés-Genis, A.; Guindo, J.; Viñolas, X.; Garcia-Niebla, J.; et al. Interatrial blocks. A separate entity from left atrial enlargement: A consensus report. J. Electrocardiol. 2012, 45, 445-451. [CrossRef] [PubMed]

20. Bayés de Luna, A.; Baranchuk, A.; Niño Pulido, C.; Martínez-Sellés, M.; Bayés-Genís, A.; Elosua, R.; Elizari, M.V. Second-Degree Interatrial block: Brief review and concept. Ann. Noninvasive Electrocardiol. 2018, 23, e12583. [CrossRef] [PubMed]

21. Waldo, A.; Bush, H.L., Jr.; Gelband, H.; Zorn, G.L., Jr.; Vitikainen, K.J.; Hoffman, B.F. Effects on the canine P waves of discrete lesions in the specialized atrial tracts. Circ. Res. 1971, 29, 452-467. [CrossRef] [PubMed]

22. Guerra, J.; Vilahur, G.; Bayés de Luna, A.; Cabrera, J.A.; Martínez-Sellés, M.; Mendieta, G.; Baranchuk, A.; Sánchez-Quintana, D. Interatrial block can occur in the absence of left atrial enlargement: New experimental model. Pacing Clin. Electrophysiol. 2020, 43, 427. [CrossRef] [PubMed]

23. Bayés de Luna, A.; Escobar-Robledo, L.A.; Aristizabal, D.; Weir Restrepo, D.; Mendieta Badimon, G.; Massó-van Roessel, A.; Elosua, R.; Bayés-Genís, A.; Martínez-Sellés, M.; Baranchuk, A. Atypical advanced interatrial block: Definition electrocardiographic recognition. J. Electrocardiol. 2018, 51, 1091-1093. [CrossRef] [PubMed]

24. Kottkamp, H. Human atrial fibrillation substrate: Towards a specific fibrotic atrial cardiomyopathy. Eur. Heart J. 2013, 34, 2731-2738. [CrossRef]

25. Bayés de Luna, A.; Martínez-Sellés, M.; Elosua, R.; Bayés-Genís, A.; Mendieta, G.; Baranchuk, A.; Breithardt, G. Relation of Advanced Interatrial block to risk of atrial fibrillation and stroke. Am. J. Cardiol. 2020, 125, 1745-1748. [CrossRef] [PubMed]

26. Bayés de Luna, A.; Martínez-Sellés, M.; Bayés-Genís, A.; Elosua, R.; Baranchuk, A. Lo que todo clínico debe conocer. What every clinician should know about Bayés Syndrome. Rev. Esp. Cardiol. (Engl. Ed.) 2020, 73, 758-762. [CrossRef]

27. Baranchuk, A. Interatrial Block and Supraventricular Arrhythmias. Clinical Implications of Bayés' Syndrome; Cardiotext Publishing: Minneapolis, MN, USA, 2017.

28. Morris, J.J., Jr.; Estes, E.H., Jr.; Whalen, R.E.; Thompson, H.K., Jr.; Mcintosh, H.D. P wave analysis in valvular heart disease Circulation 1964, 29, 242. [CrossRef] [PubMed] 
29. Rasmussen, M.U.; Fabricius-Bjerre, A.; Kumarathurai, P.; Larsen, B.S.; Dominguez, H.; Kanters, J.K.; Sajadieh, A. Common source of miscalculation and misclassification of P-wave negativity and P-wave terminal force in lead V1. J. Electrocardiol. 2019, 53, 85-88. [CrossRef] [PubMed]

30. Sajeev, J.K.; Koshy, A.N.; Dewey, H.; Kalman, J.M.; Bhatia, M.; Roberts, L.; Cooke, J.C.; Frost, T.; Denver, R.; Teh, A.W. Poor reliability of P-wave terminal force V1 in ischemic stroke. J. Electrocardiol. 2019, 52, 47-52. [CrossRef]

31. Bacharova, L.; Wagner, G.S. The time for naming the interatrial block syndrome: Bayes syndrome. J. Electrocardiol. 2015, 48, 133-134. [CrossRef] [PubMed]

32. Escobar-Robledo, L.A.; Bayés de Luna, A.; Lupón, J.; Baranchuk, A.; Moliner, P.; Martínez-Sellés, M.; Zamora, E.; de Antonio, M.; Domingo, M.; Cediel, G.; et al. Advanced Interatrial Block Predicts New-onset Atrial Fibrillation and Ischemic Stroke in Patients with Heart Failure: The "Bayes Syndrome-HF" Study. Int. J. Cardiol. 2018, 271, 174-180. [CrossRef] [PubMed]

33. Martínez-Sellés, M.; Elosua, R.; Ibarrola, M.; de Andrés, M.; Díez-Villanueva, P.; Bayés-Genis, A.; Baranchuk, A.; Bayés-de-Luna, A.; BAYES Registry Investigators. Advanced interatrial block and P-wave duration are associated with atrial fibrillation and stroke in older adults with heart disease: The BAYES registry. Europace 2020, 22, 1001-1008. [CrossRef] [PubMed]

34. Martínez-Sellés, M.; Martínez-Larrú, E.; Ibarrola, M.; Santos, A.; Díez-Villanueva, P.; Bayés-Genis, A.; Baranchuk, A.; Bayés-de-Luna, A.; Elosua, R. Interatrial block and cognitive impairment in the BAYES prospective registry. Int. J. Cardiol. 2020, 321, 95-98. [CrossRef] [PubMed]

35. Massó-van Roessel, A.; Escobar-Robledo, L.A.; Dégano, I.R.; Grau, M.; Sala, J.; Ramos, R.; Marrugat, J.; Bayés de Luna, A.; Elosua, R. Analysis of the association between electrocardiographic P-wave characteristics and atrial fibrillation in the REGICOR Study. Rev. Esp. Cardiol. (Engl. Ed.) 2017, 70, 841-847. [CrossRef]

36. Martínez-Sellés, M.; Massó-van Roessel, A.; Álvarez-Garcia, J.; Garcia de la Villa, B.; Cruz-Jentoft, A.; Vidán, M.T.; López, J.; Felix-Redondo, F.J.; Durán, J.M.; Bayés-Genís, A.; et al. (The Investigators of the Cardiac and Clinical Characterization of Centenarians (4C) registry). Interatrial block and atrial arrhythmias in centenarians: Prevalence, associations, and clinical implications. Heart Rhythm. 2016, 13, 645-651. [CrossRef]

37. de Luna, A.B.; Platonov, P.G.; García-Niebla, J.; Baranchuk, A. Atypical Advanced Interatrial block or junctional rhythm? J. Electrocardiol. 2019, 5, 85-86. [CrossRef]

38. Gentille-Lorente, D.I.; Scott, L.; Escobar-Robledo, L.A.; Mesa-Maya, M.A.; Carreras-Costa, F.; Baranchuk, A.; Martínez-Sellés, M.; Elosua, R.; Bayés-Genís, A.; Bayés-de-Luna, A. Atypical advanced interatrial block due to giant atrial lipoma. Pacing Clin. Electrophysiol. 2021, 44, 737-739. [CrossRef]

39. Chung, E.K. Aberrant atrial conduction: Unrecognized electrocardiographic entity. Br. Heart J. 1972, 34, 341-346. [CrossRef] [PubMed]

40. Julià, J.; Bayés de Luna, A.; Candell, J.; Fiol, M.; Pons, G.; Obrador, D.; Oca, F.; Trilla, E.; Vilaplana, J.; Wilke, M. Aberrancia auricular: A propósito de 21 casos. Rev. Esp. Cardiol. 1978, 31, 207. [PubMed]

41. Benito, E.M.; Bayés de Luna, A.; Baranchuk, A.; Mont, L. Extensive atrial fibrosis assessed by late gadolinium enhancement cardiovascular magnetic resonance associated with advanced interatrial block electrocardiogram pattern. Europace 2017, $19,377$. [CrossRef] [PubMed]

42. Agarwal, Y.K.; Aronow, W.S.; Levy, J.A.; Spodick, D.H. Association of interatrial block with development of atrial fibrillation. Am. J. Cardiol. 2003, 91, 882. [CrossRef]

43. Holmqvist, F.; Platonov, P.; Carlson, J.; Zareba, W.; Moss, A.J.; MADIT II Investigators. Abnormal P wave morphology is a predictor of atrial fibrillation in MADIT II patients. Ann. Noninvasive Electrocardiol. 2010, 15, 63-72. [CrossRef]

44. Enriquez, A.; Conde, D.; Hopman, W.; Mondragon, I.; Chiale, P.A.; Bayés de Luna, A.; Baranchuk, A. Advanced interatrial block is associated with recurrence of atrial fibrillation post pharmacological cardioversion. Cardiovasc. Ther. 2014, 32, 52-56. [CrossRef]

45. Enriquez, A.; Sarrias, A.; Villuendas, R.; Ali, F.S.; Conde, D.; Hopman, W.M.; Redfearn, D.P.; Michael, K.; Simpson, C.; Bayés de Luna, A.; et al. New-onset atrial fibrillation after cavotricuspid isthmus ablation: Identification of advanced interatrial block is key. Europace 2015, 17, 1289-1293. [CrossRef]

46. Sadiq Ali, F.; Enriquez, A.; Conde, D.; Redfearn, D.; Michael, K.; Simpson, C.; Abdollah, H.; Bayes de Luna, A.; Hopman, W.; Baranchuk, A. Advanced Interatrial Block Predicts New Onset Atrial Fibrillation in Patients with Severe Heart Failure and Cardiac Resynchronization Therapy. Ann. Noninvasive Electrocardiol. 2015, 20, 586-591. [CrossRef]

47. Alexander, B.; MacHaalany, J.; Lam, B.; van Rooy, H.; Haseeb, S.; Kuchtaruk, A.; Glover, B.; Bayés de Luna, A.; Baranchuk, A. Comparison of the extent of coronary artery disease in patients with versus without interatrial block and implications for new-onset atrial fibrillation. Am. J. Cardiol. 2017, 119, 1162-1165. [CrossRef]

48. Wu, J.T.; Wang, S.L.; Chu, Y.J.; Long, D.Y.; Dong, J.Z.; Fan, X.W.; Yang, H.T.; Duan, H.Y.; Yan, L.J.; Qian, P. CHADS2 and CHA2DS2-VASc scores predict the risk of ischemic stroke outcome in patients with interatrial block without atrial fibrillation. J. Atheroscler. Thromb. 2017, 24, 176-184. [CrossRef]

49. O'Neal, W.T.; Kamel, H.; Zhang, Z.M.; Chen, L.Y.; Alonso, A.; Soliman, E.Z. Advanced interatrial block and ischemic stroke. The atherosclerosis risk in communities study. Neurology 2016, 87, 352-356. [CrossRef] [PubMed]

50. Skov, M.W.; Ghouse, J.; Kühl, J.T.; Platonov, P.G.; Graff, C.; Fuchs, A.; Rasmussen, P.V.; Pietersen, Ä.; Nordestgaard, B.G.; Torp-Pedersen, G.; et al. Risk Prediction of Atrial Fibrillation Based on Electrocardiographic Interatrial Block. J. Am. Heart Assoc. 2018, 7, e008247. [CrossRef] 
51. O'Neal, W.T.; Zhang, Z.M.; Loehr, L.R.; Chen, L.Y.; Alonso, A.; Soliman, E.Z. Electrocardiographic advanced interatrial block and atrial fibrillation risk in the general population. Am. J. Cardiol. 2016, 117, 1755-1759. [CrossRef] [PubMed]

52. Magnani, J.W.; Gorodeski, E.Z.; Johnson, V.M.; Sullivan, L.M.; Hamburg, N.M.; Benjamin, E.J.; Ellinor, P.T. P wave duration is associated with cardiovascular and all-cause mortality outcomes: The National Health and Nutrition Examination Survey. Heart Rhythm. 2011, 8, 93-100. [CrossRef]

53. Maheshwari, A.; Norby, F.L.; Soliman, E.Z.; Alraies, M.C.; Adabag, S.; O’Neal, W.T.; Alonso, A.; Chen, L.Y. Relation of prolonged P-wave duration to risk of sudden cardiac death in the general population (from the Atherosclerosis risk in Communities Study). Am. J. Cardiol. 2017, 119, 1302-1306. [CrossRef] [PubMed]

54. Gutierrez, A.; Norby, F.L.; Maheshwari, A.; Rooney, M.R.; Gottesman, R.F.; Mosley, T.H.; Lutsey, P.L.; Oldenburg, N.; Soliman, E.Z.; Alonso, A.; et al. Association of abnormal P-wave indices with dementia and cognitive decline over 25 years: ARIC-NCS (The Atherosclerosis Risk in Communities Neurocognitive Study). J. Am. Heart Assoc. 2019, 8, e014553. [CrossRef] [PubMed] 